\title{
CRITICAL ANALYSIS OF ARTIFICIAL TEETH FOR ENDODONTIC TEACHING
}

\author{
Maria Renata Giazzi NASSRI ${ }^{1}$, Jaime CARLIK ${ }^{2}$, Camila Roberta Nepomuceno da SILVA ${ }^{3}$, Renata Elisa OKAGAWA ${ }^{3}$, Suzy LIN ${ }^{3}$
}

1- PhD, Professor of Endodontics and Dental Clinic, School of Dentistry, University of Mogi das Cruzes, Mogi das Cruzes, SP, Brazil.

2- PhD, Professor of Endodontics, School of Dentistry, University of Mogi das Cruzes, Mogi das Cruzes, SP, Brazil.

3- Undergraduate Students, School of Dentistry, University of Mogi das Cruzes, Mogi das Cruzes, SP, Brazil.

Corresponding address: Maria Renata Giazzi NASSRI - Mogi das Cruzes University - Dentistry School - Departament of Endodontics. Av. Dr. Cândido Xavier de Almeida Souza, 200, Centro Cívico - 08780-911, Mogi das Cruzes, SP Brasil - Phone: 55 11 $4798-7138$ e-mail: renassri@umc.br

Received: May 11, 2007 - Modification: August 10, 2007 - Accepted: October 5, 2007

\begin{abstract}
$\Gamma_{\text {he }}$ and submitted to 18 profection cloudy resin artificial teeth: internal and external anatomy; coronal chambers regarding their size, shape and canal path; root canal regarding their size, shape and position; fulfillment of the pulp chamber and root canals by considering the texture, quantity, color, and ease of handling; resin hardness and visualization of the radiographic image. The results presented favorable opinions, in terms of internal and external anatomy, coronal pulp chambers and root canal and handling and radiographic imaging. The contents of the pulp space and hardness of the teeth were considered satisfactory. The average grade assigned to the artificial tooth quality was 8.4 , in a $0-10$ scale. In conclusion, the artificial teeth have potential to replace the natural teeth in endodontic teaching; however, improvements are still necessary to reach a better quality model.
\end{abstract}

Uniterms: Endodontics teaching. Teaching model. Tooth artificial.

\section{INTRODUCTION}

For decades, endodontic teaching has relied almost exclusively on the use of natural human teeth. Practice on extracted teeth has been a universal method of teaching preclinical endodontics and giving students the opportunity of gaining expertise before moving to patients. Crossinfection control, originated by the manipulation of extracted teeth, among other reasons, is threatening such practice in some teaching institutions.

Dummer, et al. ${ }^{1}$ (1991) introduced the use of uniform resin blocks, completely different from the natural teeth, which could reproduce root canal curve. The application of these resin blocks was initially for laboratory-based research, but their use for teaching purposes has been widespread.

Peterson ${ }^{8}$ (1980) presented an introductory study about artificial teeth produced with a kind of wax by modeling selected natural teeth in many directions. Although he could partly reproduce root canals, reproduction of enamel and dentin anatomy was more challenging. Kahn ${ }^{5}$ (1983), Jackson and Tidmarsh ${ }^{4}$ (1993) and Sauveur and Boucher ${ }^{11}$ (1998) created endodontic models with teeth made of wax or resin, but without the characteristics of natural teeth. Reader, et al. ${ }^{10}$ (1994) highlighted a number of reasons why the use of natural teeth was not indicated in endodontic teaching, including frequent concerns about infection control and difficult in standardization, all these posing difficulties to teaching.

Natural teeth have been the major resource in endodontic teaching in Brazil. In 2005, Nassri, et al. ${ }^{7}$ published a study that presented teeth constructed from opaque and translucent resin that resemble the natural teeth.

The artificial teeth used in this study are produced by the Brazilian company "Fábrica de Sorrisos" (Smile Factory). The teeth are fabricated individually, one by one, and the assembly of cutting of the teeth is established by a millimeterbased fitting process. Each tooth costs US\$ 6,00 (six dollars). The endodontic team of the University of Mogi das Cruzes was requested to design these teeth and thus try to reproduce, as close as possible, the characteristics of the natural teeth. There is no trade relation or financial advantage in this partnership.

The purpose of this work was to evaluate the anatomic, physical and radiographic features of artificial teeth for 
endodontic teaching based on the evaluation by professors of Endodontics.

\section{MATERIALS AND METHODS}

This study was submitted to the Ethics in Human Research Committee of the University of Mogi das Cruzes to ensure the voluntary participation of the examiners and was approved under the register number 08/2006.

The artificial teeth were produced by a Brazilian factory called "Fábrica de Sorrisos" (Smile Factory) and involved endodontic specialist professors of the University of Mogi das Cruzes to give directions on the tooth design. These teeth are now being distributed as "artificial tooth UMC model", although there is no commercial UMC involvement in the trade.

Eighteen professors of Endodontics from different Brazilian universities were invited to take part in this study and received a kit containing five cloudy resin artificial teeth: a maxillary central incisor (Figure 1A), a mandibular central incisor (figure 1A), a maxillary first premolar (Figure 1B), a maxillary molar and a mandibular molar (Figure 1C). These teeth were selected to represent a rage of tooth groups. Although the transparent resin artificial teeth (sound and with pulp pathologies) (Figures 2A, 2B, 3A and 3B) were not included in this study, each participant received a sample to be aware of their existence and also to have the opportunity to handle them.

A questionnaire with 14 closed questions was attached to the kit (see attachment 1). There were few lines at the end of each question where the participants could make comments on the general quality of the artificial teeth. At the last question, a grade, from zero to ten, had to be attributed to them. These questions were related to the anatomic and radiographic features, texture, fulfillment and hardness. After a critical analysis made by the specialists, the performance of the teeth was rated as excellent, satisfactory, unsatisfactory and poor.

In order to make this analysis more complete and efficient, the professors of Endodontics were asked to simulate all phases, including radiographic imaging (Figures 4A, 4B and 4C), of the conventional hand-held endodontic treatment in each one of the cloudy resin artificial teeth. Before answering the questionnaire, they had to have completed five endodontic treatments in five different kinds of teeth, as described above. The following procedures were accomplished: access surgery using spherical burs for the trepanation; removal of the pulp chamber roof and suitable shaping; pulpotomy, which consisted on the removal of the fulfilling gel that simulates the pulp tissue inside the vital teeth pulp chamber; access and measurement of the root canal, which allowed visualizing the contrast between the radiographic image of the dental structure and the stainless steel file (figures 5A, 5B and 5C); root canal instrumentation using the conventional technique; the main cone fitting and root canal obturation.

Thereafter, the participants were asked to answer the questionnaire.

\section{RESULTS}

Most questions were answered with "excellent" or "satisfactory", although the items regarding the fulfillment of the coronal chamber and resin hardness were rated as "unsatisfactory" and "poor" by some participants. These answers were, however, in a smaller number compared to

TABLE 1- Percentages obtained from the answers to the items of the questionnaires

\begin{tabular}{|c|c|c|c|c|c|}
\hline \multicolumn{2}{|l|}{$\begin{array}{l}\text { Evaluation options } \\
\text { Analyzed Item }\end{array}$} & \multirow{2}{*}{$\begin{array}{l}\text { Great } \\
86 \%\end{array}$} & \multirow{2}{*}{$\begin{array}{c}\text { Satisfactory } \\
13 \%\end{array}$} & \multirow{2}{*}{$\begin{array}{c}\text { Unsatisfactory } \\
-\end{array}$} & \multirow{2}{*}{$\begin{array}{r}\text { Poor } \\
-\end{array}$} \\
\hline External Anatomy & & & & & \\
\hline \multirow[t]{2}{*}{ Internal Anatomy } & & $86 \%$ & $13 \%$ & - & - \\
\hline & Size & $80 \%$ & $20 \%$ & - & - \\
\hline Coronary & Form & $73 \%$ & $26 \%$ & - & - \\
\hline Chamber & Access to root canals & $73 \%$ & $26 \%$ & - & - \\
\hline \multirow[t]{3}{*}{ Root Canal } & Size & $66 \%$ & $33 \%$ & - & - \\
\hline & Form & $73 \%$ & $23 \%$ & - & - \\
\hline & Localization & $86 \%$ & $13 \%$ & - & - \\
\hline Fulfilling of Root & Texture & $33 \%$ & $60 \%$ & $3,6 \%$ & $3 \%$ \\
\hline Chamber and & Amount & $46 \%$ & $53 \%$ & - & - \\
\hline Root Canals & Coloration & $73 \%$ & $26 \%$ & - & - \\
\hline \multicolumn{2}{|c|}{ Easiness of Manipulation } & $46 \%$ & $46 \%$ & $7 \%$ & - \\
\hline \multicolumn{2}{|l|}{ Hardness } & $6,6 \%$ & $60 \%$ & $33 \%$ & - \\
\hline \multicolumn{2}{|c|}{ Visualization of Radiographic Image } & $46 \%$ & $46 \%$ & $7 \%$ & - \\
\hline
\end{tabular}




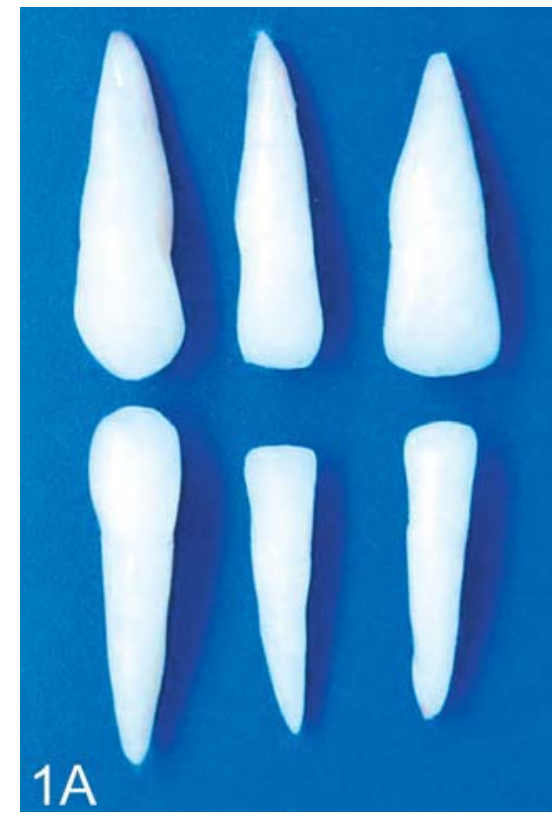

FIGURE 1A- Cloudy resin anterior teeth

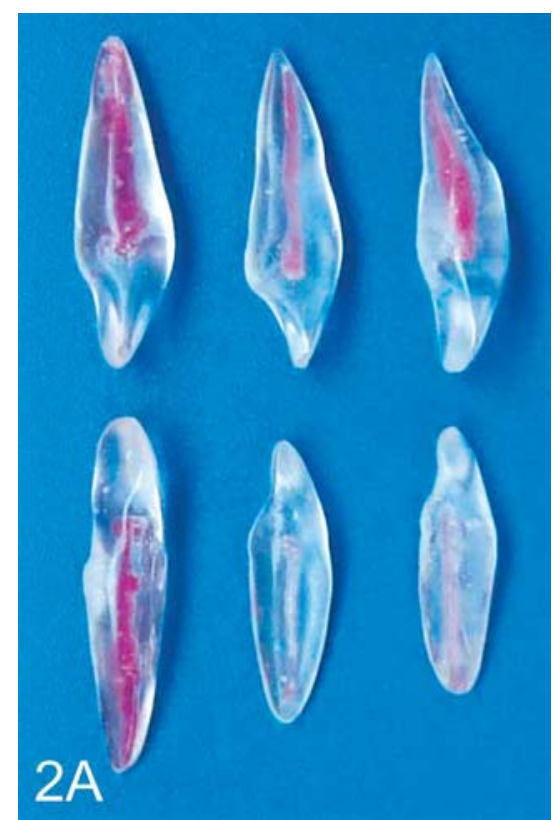

FIGURE 2A- Transparent resin anterior teeth

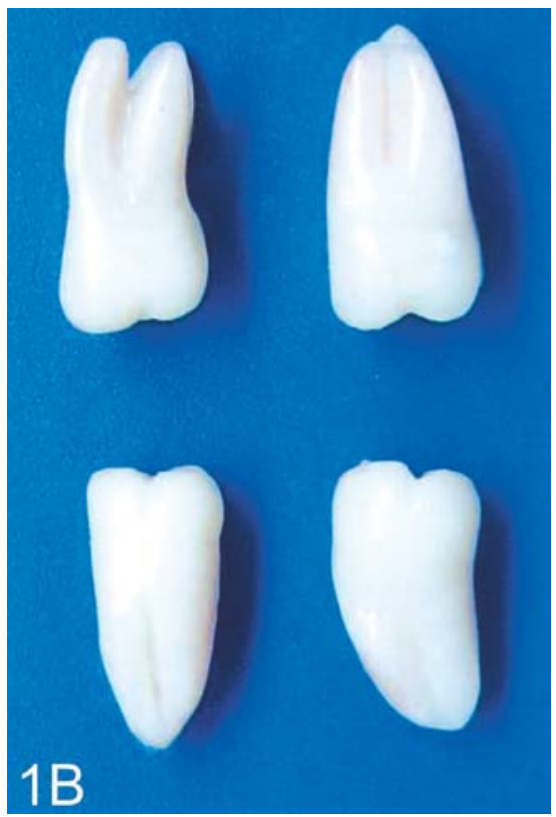

FIGURE 1B- Cloudy resin premolars

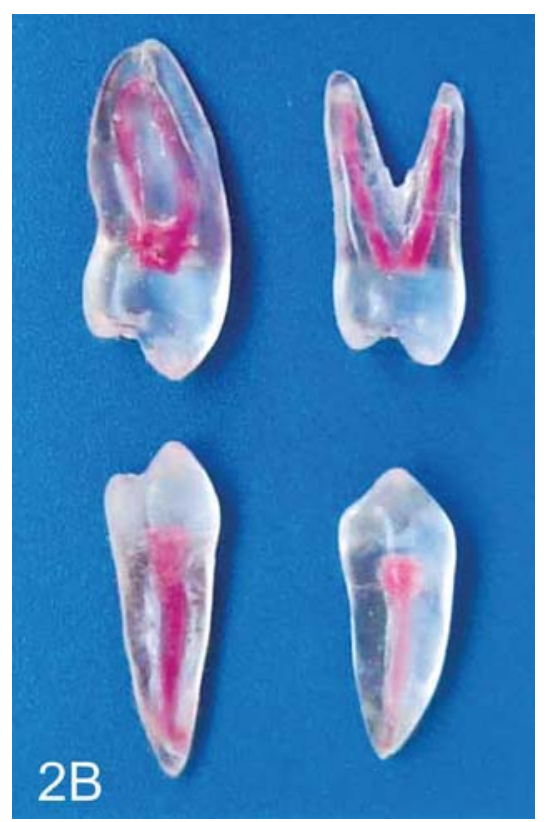

FIGURE 2B- Transparent resin premolars

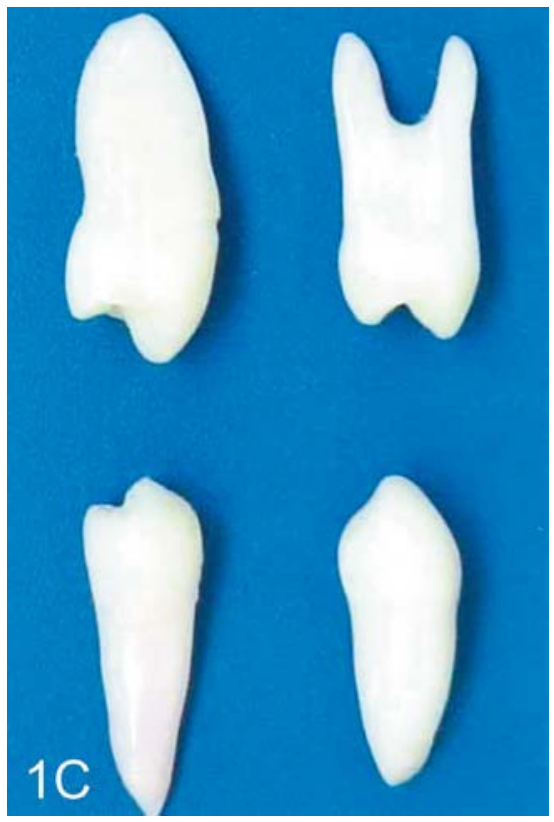

FIGURE 1C- Cloudy resin molars

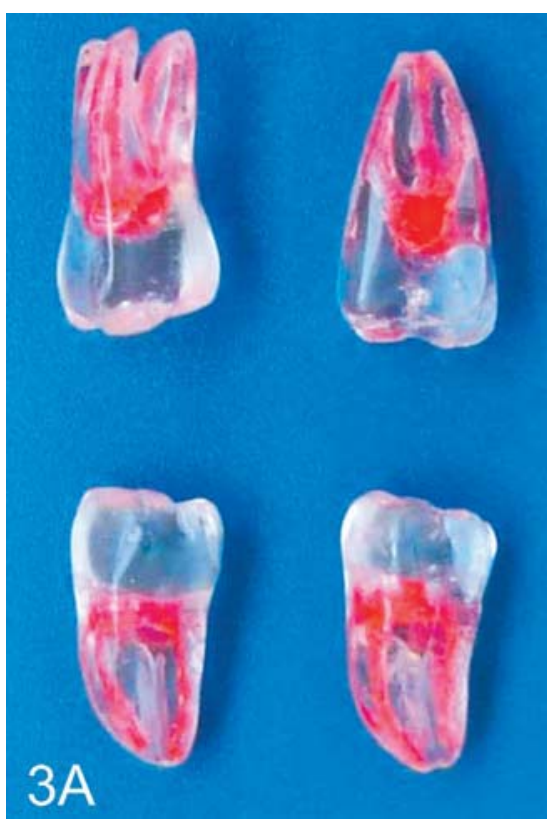

FIGURE 3A- Transparent resin molars

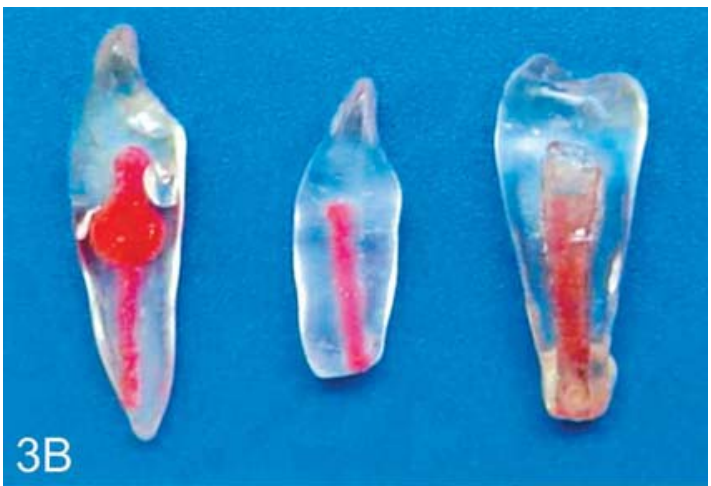

FIGURE 3B- Simulated pulp pathologies: internal resorption, external resorption, and periapical lesion associated with pulp mortification 


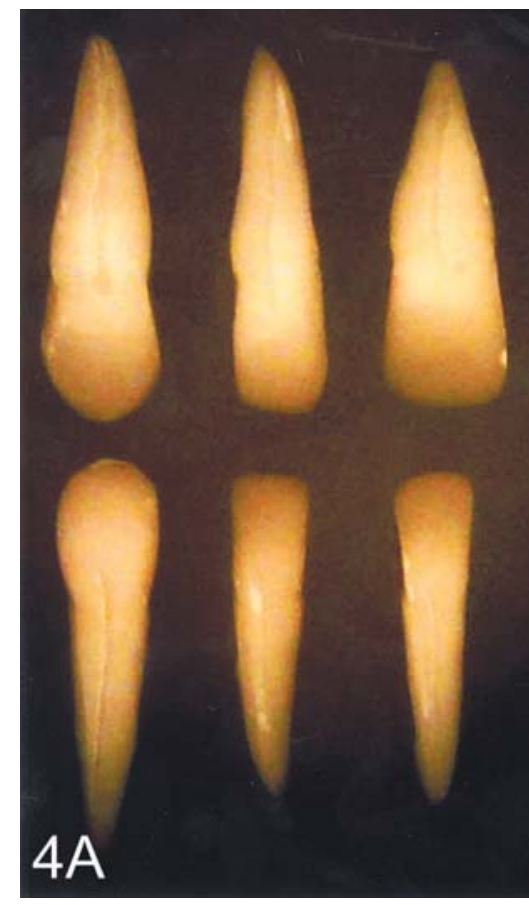

FIGURE 4A- Radiographic image of cloudy resin anterior teeth

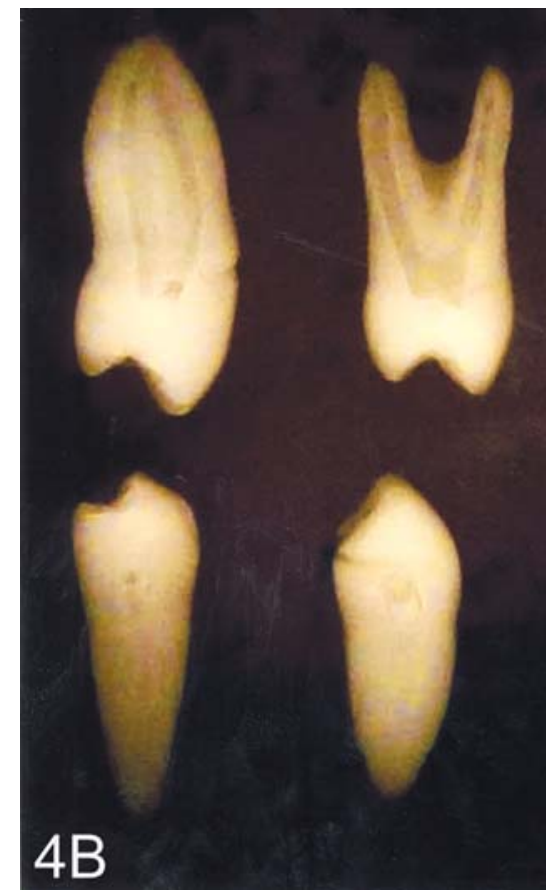

FIGURE 4B- Radiographic image of cloudy resin premolars

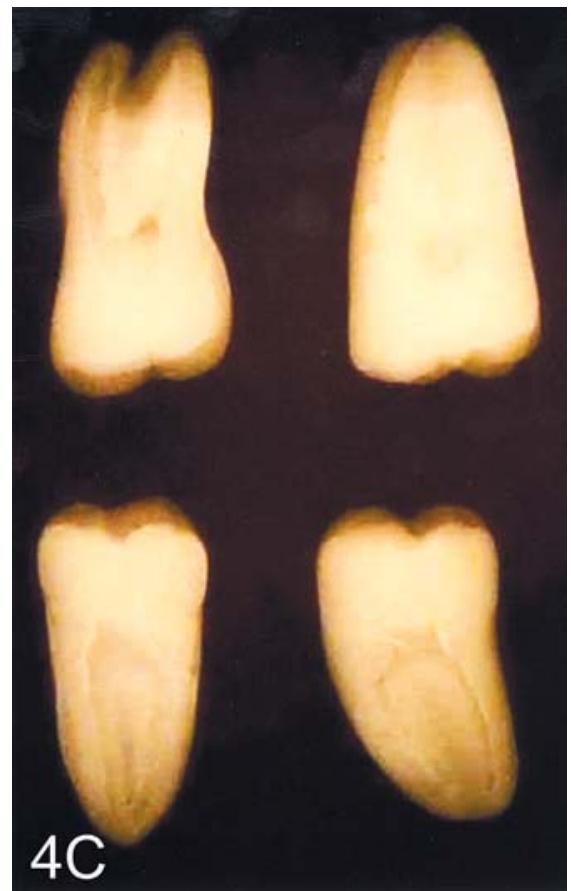

FIGURE 4C- Radiographic image of cloudy resin molars

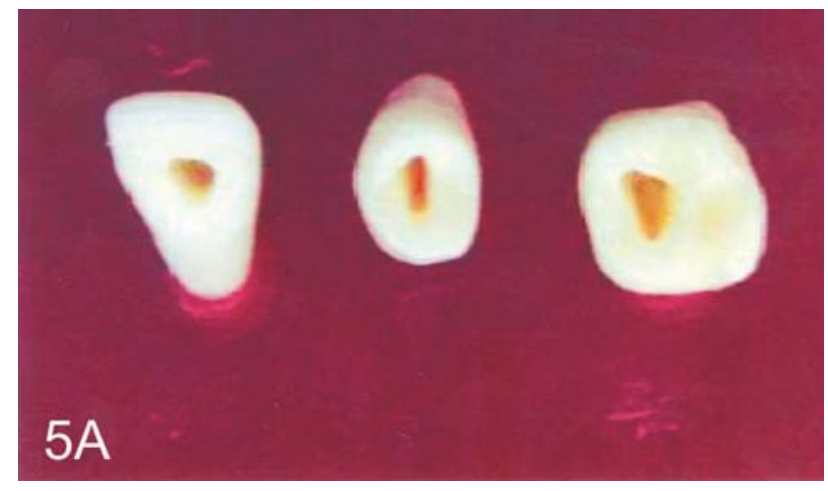

FIGURE 5A- Root canal access of maxillary artificial teeth

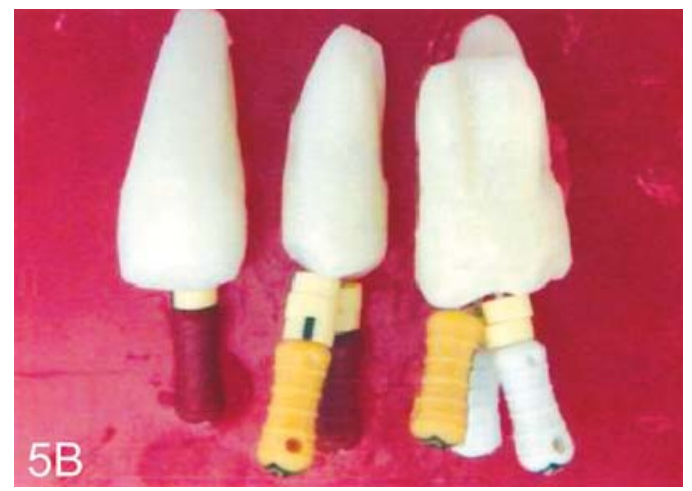

FIGURE 5B- Endodontic files to determine root canal length

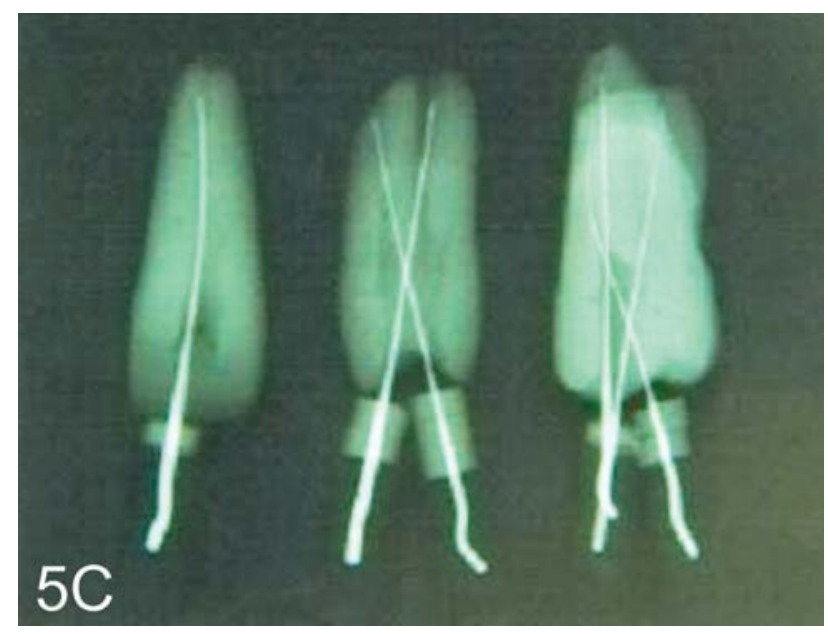

FIGURE 5C- Radiographic image of root canal length 


\section{Attachment 1}

QUESTIONNAIRE

1. External anatomy:

( ) excellent

( ) satisfactory

( ) unsatisfactory

( ) poor

Commentary:
2. Internal anatomy:
( ) excellent
( ) satisfactory
( ) unsatisfactory
( ) poor
Commentary:
3. Coronary chamber - size:
( ) excellent
( ) satisfactory
( ) unsatisfactory
( ) poor

Commentary:

4. Coronary chamber - shape:

( ) excellent

( ) satisfactory

( ) unsatisfactory

( ) poor

Commentary:

5. Coronary chamber - access to the root canals:

( ) excellent

( ) satisfactory

( ) unsatisfactory

( ) poor

Commentary:
6. Root canal - size:
( ) excellent
( ) satisfactory
( ) unsatisfactory
( ) poor
Commentary:

\section{Root canal - shape:}

( ) excellent

( ) satisfactory

( ) unsatisfactory

( ) poor

Commentary:

8. Root canal - localization:

( ) excellent

( ) satisfactory

( ) unsatisfactory
( ) poor

Commentary:

9. Fulfillment of the coronary chamber and root canal texture:
( ) excellent
( ) satisfactory
( ) unsatisfactory
() poor
Commentary:

10. Fulfillment of the coronary chamber and root canal quantity:
( ) excellent
( ) satisfactory
( ) unsatisfactory
() poor
Commentary:

11. Fulfillment of the coronary chamber and root canal color:
( ) excellent
( ) satisfactory
( ) unsatisfactory
( ) poor
Commentary:

12. Manipulation easiness

( ) excellent

( ) satisfactory

( ) unsatisfactory

( ) poor

Commentary:

13. Hardness:

( ) excellent

( ) satisfactory

( ) unsatisfactory

( ) poor

Commentary:

14. Visualization of the radiographic image:
( ) excellent
( ) satisfactory
( ) unsatisfactory
( ) poor

Commentary:

Please, give a grade to the general quality of the teeth, in a 0 to 10 scale, wherein 0 is the worst grade and 10 is the best one: Grade: 
the other options.

The collected data were tabulated and are presented as percentages on Table 1. Regarding the grade, the average was 8.4 , from 0 to 10 .

\section{DISCUSSION}

Endodontic teaching has always been based on the use of natural human teeth. Because of the difficulty in getting teeth, some authors have tried to develop alternatives. Resin blocks, which simulate root canals, but without reproducing the complex internal and external dental anatomy, have been proposed by Marini, et al. ${ }^{6}$ (1986) and by Dummer, et al. ${ }^{1}$ (1991). Artificial wax tooth models have also been created by Peterson $^{8}$ (1980) and Hasselgren and Tronstand, et al. ${ }^{3}$ (1975).

After these first attempts, the need of developing artificial tooth models with better quality was recognized. Other authors tried to produce models that could fit the natural teeth by simulating the bone density of the maxillary and mandibular arches (Steiner and Hassel ${ }^{12}, 1972 ; \mathrm{Kahn}^{5}$, 1983; Jackson and Tidmarsch ${ }^{4}$, 1993; Sauveur and Boucher ${ }^{11}$, 1998). In 2005, Nassri, et al. ${ }^{7}$ aided the "Fábrica de Sorrisos" to create artificial teeth, one by one, in an attempt to reproduce their internal and external anatomy, hardness, radiographic image and pulp tissue in the different tooth groups. As these teeth had a good acceptance, they have been used in some Brazilian universities as possible alternatives to replace the natural teeth. These teeth have been developed in opaque and translucent resin, like reported elsewhere ${ }^{3,9}$. In 1994, Reader, et al. ${ }^{10}$ made experiments with a similar artificial tooth model, but without refinement. With the tooth developed by Nassri, et al. ${ }^{7}$ (2005), there was a need to evaluate them properly. The results of the present study showed that these teeth have potential to replace the natural ones by allowing the establishment of a standardized endodontic methodology because it is possible to obtain a variation at the degree of difficulty by creating teeth that simulate pulp pathologies. Replacement of the use of the natural teeth by resin teeth would meet two situations: the first, is related to the Dentistry teaching and reflects the current conservative philosophy of preserving the natural teeth as much as possible, which interferes directly with tooth removal and makes ever more difficult to get natural teeth for teaching purposes; the second, is related to the Ethics Committee' guidelines regarding tooth origin, as in many cases the teeth are obtained from popular dental offices, without any official record. These facts, together, have substantiated the replacement of natural teeth by artificial teeth.

From the gathered data, it is possible to conclude that some features still need to be improved. According to the endodontists, who took part in this study, the content of the coronary chamber and the root canal have a viscosity level different from that of the pulp tissue, which makes difficult its removal. The visualization of the radiographic image has low-level contrast, although hard and soft tissues are clearly distinguishable. The main difficulty is the resin hardness, which does not reproduce the dentin hardness, giving the wrong impression that there is not too much resistance in accessing the pulp tissue in a natural tooth.

On the other hand, the other characteristics were well accepted by the participants, which makes feasible to replace the natural teeth by the artificial ones in the endodontic teaching.

The artificial teeth present many advantages, such as: ease of obtaining and replacement, which is a very common occurrence due to the lack of experience of the students; they can be manufactured by simulating dental illnesses as periapical injury, pulp mortification, root canal narrowing due to pulp metabolic alteration or even dentist's errors as root canal rectification, root perforation and others. In their preliminary study, Nassri, et al. ${ }^{7}, 2005$ showed that the internal and external anatomies are compatible and the radiographic imaging is also satisfactory.

There are not yet sufficient reported studies to trace an outline of this technique, which is an innovation in endodontic teaching. The adoption of resin teeth in dental school can be a useful tool and might improve students' teaching-learning conditions.

\section{CONCLUSION}

The artificial teeth have potential to replace the natural teeth in endodontic teaching; however, improvements are still necessary to reach a better quality model.

\section{ACKNOWLEDGMENTS}

The authors thank the Fábrica de Sorrisos (Smile Factory) for the teeth used in this study and SBPqO (Brazilian IADR division - International Association of Dental Research) for the first place award at the Research-Teaching Prize, 2006.

\section{REFERENCES}

1- Dummer PMH, Alodeh MHA, Al-Omari MAO. A method for the construction of simulated root canals in clear resin blocks. Int Endod J. 1991;24:631-6.

2- Hasselgren G, Nellestam P, Bynum-Hasselgren R. Teeth with transparent roots - an improved teaching aid for preclinical endodontics. J Endod. 1987;13(3):126-7.

3- Hasselgren G, Tronstad L. The use of transparent teeth in the teaching of preclinical endodontics. J Endod. 1975;1(8):278-80.

4- Jackson AP, Tidmarsh G. Simulation models for teaching endodontic surgical procedures. Int Endod J. 1993;26:198-200.

5- Kahn HA. Preclinical dentec for teaching endodontic procedures. J Endod. 1983;9(11):506-9.

6- Marini R, Bellagarda M, Lorenzetti M. L'uso dei simulatori endodontici nell'apprendimento pré-clinico delle tecniche strumentali. Minerva Stomatol. 1986;35:307-12. 
7- Nassri MRG, Carlik J, Souza NJA, Montezel JL, Maekawa LE, Oliveira S. Modelo de dentes artificiais com canais simulados para treinamento da Técnica Endodôntica por alunos de graduação. Braz Oral Res. 2005;19(suppl):21.

8- Peterson WR. A technique for preparing an artificial tooth for endodontic access preparation. J Endod. 1980;6:490-4.

9- Pinsky LD, Tilk MA Further observations on the use of transparent teeth in the teaching of preclinical endodontics. J Endod. 1979;5(6):192.

10- Reader MC, Kleier DJ, Wagner-Bujanda S. Anatomical artificial teeth for teaching preclinical endodontics. J Dent Educ. 1994;58:22932 .

11 - Sauveur G, Boucher Y. A teaching model for endodontic surgery. Int Endod J. 1998;31:133-6.

12- Steiner JC, Van Hassel HJ. An effective endodontic teaching manikin. J Dent Educ. 1972;36:26-9. 